\title{
Biological manganese removal from mine drainage in a fixed-bed bioreactor at pilot-scale
}

\author{
J Jacob $B R G M$, France \\ I Raignault Rio Tinto SA, France \\ F Battaglia-Brunet $B R G M$, France \\ C Mailhan-Muxi Rio Tinto SA, France \\ J Engevin $B R G M$, France \\ M Djemil BRGM, France
}

\begin{abstract}
The closed underground fluorspar Burg mine (Rio Tinto France) produces a near-neutral mine drainage ( $\mathrm{pH}$ 6.3) with high concentrations of iron and manganese (14 mg. $\mathrm{L}^{-1}$ and $12 \mathrm{mg} \cdot \mathrm{L}^{-1}$, respectively). Average flow rate is $27 \mathrm{~m}^{3} . h^{-1}$. A passive water treatment is being developed by $B R G M$, the French geosurvey to replace the current lime treatment by a more environmentally friendly, economical and lower sludge producing technology. Different set-up and operating conditions were investigated at laboratory scale and are still currently being optimised at pilot-scale. The pilot consists of a $1 \mathrm{~m}^{3}$ settling tank, in which iron $\left(\mathrm{Fe}^{2+}\right)$ is oxidised and iron hydroxides are settled, followed by an upflow $1 \mathrm{~m}^{3}$ fixed-bed bioreactor filled with a mixture of limestone and pyrolusite $\left(\mathrm{MnO}_{2}\right)$ and supplied with air, in which manganese precipitates. The fixed-bed was inoculated with sludges coming from two passive mine drainage treatment plants in which some manganese removal occurs. Residence time ranged from $50 \mathrm{~h}$ to $20 \mathrm{~h}$. Results are promising: maximum removal rates were 99\% for both iron and manganese. Iron and manganese concentrations were decreased under the $1 \mathrm{mg} \cdot \mathrm{L}^{-1}$ standard. Iron removal rate in the settling tank varied from $80 \mu \mathrm{g} \cdot \mathrm{L}^{-1} \cdot \mathrm{h}^{-1}$ to $160 \mu \mathrm{g} \cdot \mathrm{L}^{-1} \cdot \mathrm{h}^{-1}$. Manganese removal rate in the bioreactor ranged from $130 \mu \cdot L^{-1} \cdot h^{-1}$ to $350 \mu \cdot L^{-1} \cdot h^{-1}$. Surprisingly, up to $38 \%$ of the manganese was removed in the settling tank at low residence time. Residence time and aeration rate are still being optimised and clogging is being assessed. Currently, the pilot has been operating for 6 months and will continue to operate for another 6 months.
\end{abstract}

Keywords: mine drainage, passive water treatment, iron, manganese, bioreactor

\section{Introduction}

Manganese and iron are major contaminants of large range of mine drainages (United States Environmental protection Agency 2014). High concentrations of manganese can cause toxicity in aquatic and terrestrial ecosystems (Howe et al. 2004). In humans, manganese can be a toxic substance when present in excessive concentrations in air, water and food (United States Department of Health and Human Services 2012). In France, the quality standard for manganese in waters used for human consumption is $50 \mu \mathrm{g} \cdot \mathrm{L}^{-1}$.

The removal of manganese from mine drainage has been extensively studied for years. Neculita \& Rosa (2018) recently produced an excellent review on manganese in mine drainage and the means to treat it. The most widespread passive manganese treatments for mine drainage, such as oxic rock filters (Tan et al. 2010) or the patented pyrolusite process (Vail \& Riley 2000), use microorganisms to improve manganese oxidation rate without increasing $\mathrm{pH}$ up to 10 . Many different microorganisms can remove manganese from water by oxidising it as a precipitate through a wide variety of pathways (Barboza et al. 2016). 
The closed Burg mine in France produces a circumneutral mine drainage with relatively high concentrations of iron and manganese. A passive treatment is currently being tested to replace lime treatment. The objective of this study is to evaluate and optimise the size and the footprint of this passive treatment process through an onsite pilot plant experiment.

\section{Methodology}

\subsection{Mine site and mine water description}

The Burg mine was an underground mine located in the southwest of France and operated since 1954 for fluorspar $\left(\mathrm{CaF}_{2}\right)$ extraction by Sogerem, a company which is today part of Rio Tinto group. The extracted ore contained massive fluorspar with $95 \%$ calcium fluoride. The Burg mine geological substratum is formed of Albigeois's shale, a complex system of shale, sandstone, and quartzite with low permeability. The fluorspar production ceased in 2006 after fifty years of activity, for economic reasons after the other near-by two main fluorspar open pit mines owned by Sogerem ceased operations due to the exhaustion of the orebody. Mine drainage first appeared fifteen months after dewater stopped. The mine drainage was initially slightly acidic and contained high levels of iron, manganese and fluorine. Since 2007, water has been treated with a lime process. The water quality objectives are to decrease fluorine concentration below $15 \mathrm{mg} . \mathrm{L}^{-1}$ and iron and manganese concentrations below $1 \mathrm{mg} \cdot \mathrm{L}^{-1}$. The concentrations of contaminants present in the mine water have decreased significantly over time. Currently the major contaminants in Burg mine water are iron and manganese, whereas fluorine concentration has decreased below the water quality objective and thus no longer requires treatment (Table 1). The surface area available on site to implement a passive treatment plant is limited. The treatment must therefore be optimised to minimise the footprint of the plant. Burg mine water alkalinity is $240 \mathrm{mg} \cdot \mathrm{L}^{-1}$ calcium carbonate $\left(\mathrm{CaCO}_{3}\right)$. Sulphate concentration ranges from $200 \mathrm{mg} \cdot \mathrm{L}^{-1}$ to $300 \mathrm{mg} \cdot \mathrm{L}^{-1}$, and the average water flow rate is $27 \mathrm{~m}^{3} \cdot \mathrm{h}^{-1}$.

Table 1 Main characteristics of Burg mine water (average values of 38 analyses over a six-month period in 2018)

\begin{tabular}{lll}
\hline Parameter & Units & Burg mine water \\
\hline $\mathrm{pH}$ & & 6.33 \\
Dissolved oxygen & $\mathrm{mg} . \mathrm{L}^{-1}$ & 2.70 \\
Temperature & ${ }^{\circ} \mathrm{C}$ & 16.2 \\
Conductivity & $\mu \mathrm{S} . \mathrm{cm}^{-1}$ & 581 \\
Dissolved Fe & $\mathrm{mg} \cdot \mathrm{L}^{-1}$ & 13.5 \\
Dissolved $\mathrm{Mn}$ & $\mathrm{mg} \cdot \mathrm{L}^{-1}$ & 11.6 \\
Dissolved $\mathrm{F}$ & $\mathrm{mg} \cdot \mathrm{L}^{-1}$ & 7.6 \\
\hline
\end{tabular}

\subsection{Experimental set-up}

The pilot plant consists of an aeration tank, a settling tank for removal of iron and a fixed-bed bioreactor for the removal of manganese (Figure 1). The pilot plant was fed by a GA10 diaphragm pump (MILTON ROY) that enables flow rates from 0 to $18 \mathrm{~L} . \mathrm{h}^{-1}$. 


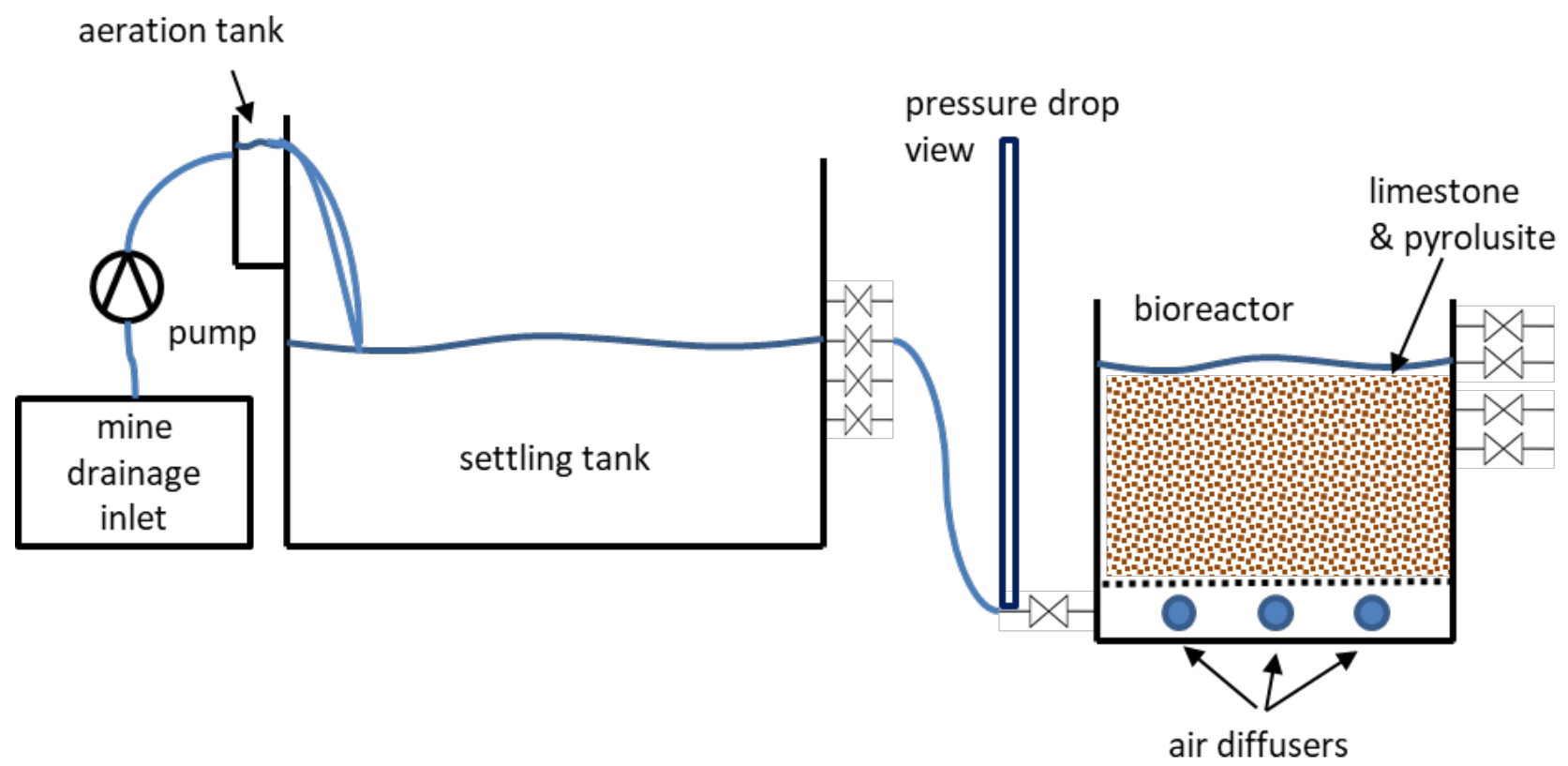

Figure 1 Sketch diagram of the pilot plant

The aeration tank was a $7 \mathrm{~L}$ tank with a $\mathrm{V}$-notch weir placed $0.5 \mathrm{~m}$ above the settling tank. The settling tank was made from a $2 \mathrm{~m}^{3}$ polyethylene water transport tank $(1.54 \mathrm{~m} \times 2.23 \mathrm{~m})$. Four outlets were created to modify the tank's volume: 750, 900, 1050 or $1200 \mathrm{~L}$. The settling tank was raised $0.8 \mathrm{~m}$ above the bioreactor to feed it by gravity.

The fixed-bed bioreactor was made from a $1 \mathrm{~m}^{3} \mathrm{PVC}$ Intermediate Bulk Containers $(1.0 \mathrm{~m} \times 1.2 \mathrm{~m})$. The design of this bioreactor enables four water volumes: $230,280,330$, and $400 \mathrm{~L}$. The bioreactor was filled with a mix of $91 \%(\mathrm{~m} / \mathrm{m})$ limestone gravel (Milhau Company) and $9 \%$ pyrolusite $\left(\mathrm{MnO}_{2}\right)$ sand (Water Concept Company). A small biological inoculum coming from two passive mine drainage treatment plants in which some manganese removal occurs was also added. The particles size of the limestone was $20-40 \mathrm{~mm}$ and it was composed of $44 \%$ calcium carbonate and $48 \%$ dolomite $\left(\mathrm{CaMg}\left(\mathrm{CO}_{3}\right)_{2}\right)$. The particles size of the pyrolusite was 0.3-0.8 $\mathrm{mm}$ and it contained $80 \%$ of pyrolusite.

Aeration was provided by three ethylene propylene diene monomer cylindrical air diffusers of $0.75 \mathrm{~m}$ placed below the limestone and three air pumps. Three rotameters were used to control the airflow rate. A grid with a mesh of $2 \mathrm{~cm} \times 2 \mathrm{~cm}$ was set up between the air diffusers and the fixed-bed to prevent clogging of the aeration system and channelling in the bed. A transparent graduated tube was installed between the tank and the bioreactor to read the water height and therefore the pressure drop.

\subsection{Investigated conditions}

This paper presents the results after 147 days of pilot operation, which covers the period from July to December 2018. During this period, the water volume of the settling tank was set to $1050 \mathrm{~L}$ and the bioreactor was set to $350 \mathrm{~L}$. The total airflow rate in the bioreactor was about $1 \mathrm{~L} \cdot \mathrm{min}^{-1}$.

Three operating conditions were investigated. Condition 1 lasts from day 1 to day 27 with a water flow rate of $7 \mathrm{~L} . \mathrm{h}^{-1}$. On day 27 , the aeration tank was removed and water flow rate was maintained at 7 L.h $\mathrm{h}^{-1}$ until day 76 for condition 2. From day 76 to day 103, water flow rate was 11 L.h $^{-1}$, but on day 103 the water pump broke down and it was decided to change the water flow rate. The results of this period are not significant because it did not last long enough. During condition 3, from day 105 to day 147, water flow rate was 17 L.h ${ }^{-1}$.

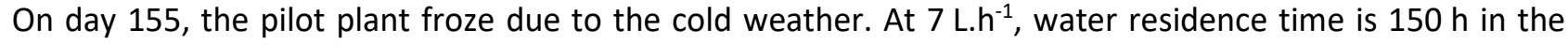

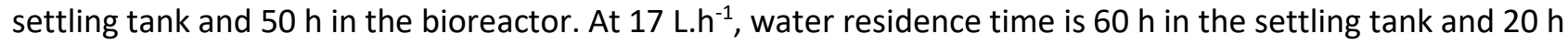
in the bioreactor. Residence times were calculated taking into account the porosity of the limestone in the fixed-bed bioreactor. A picture of the pilot plant is presented in Figure 2. 

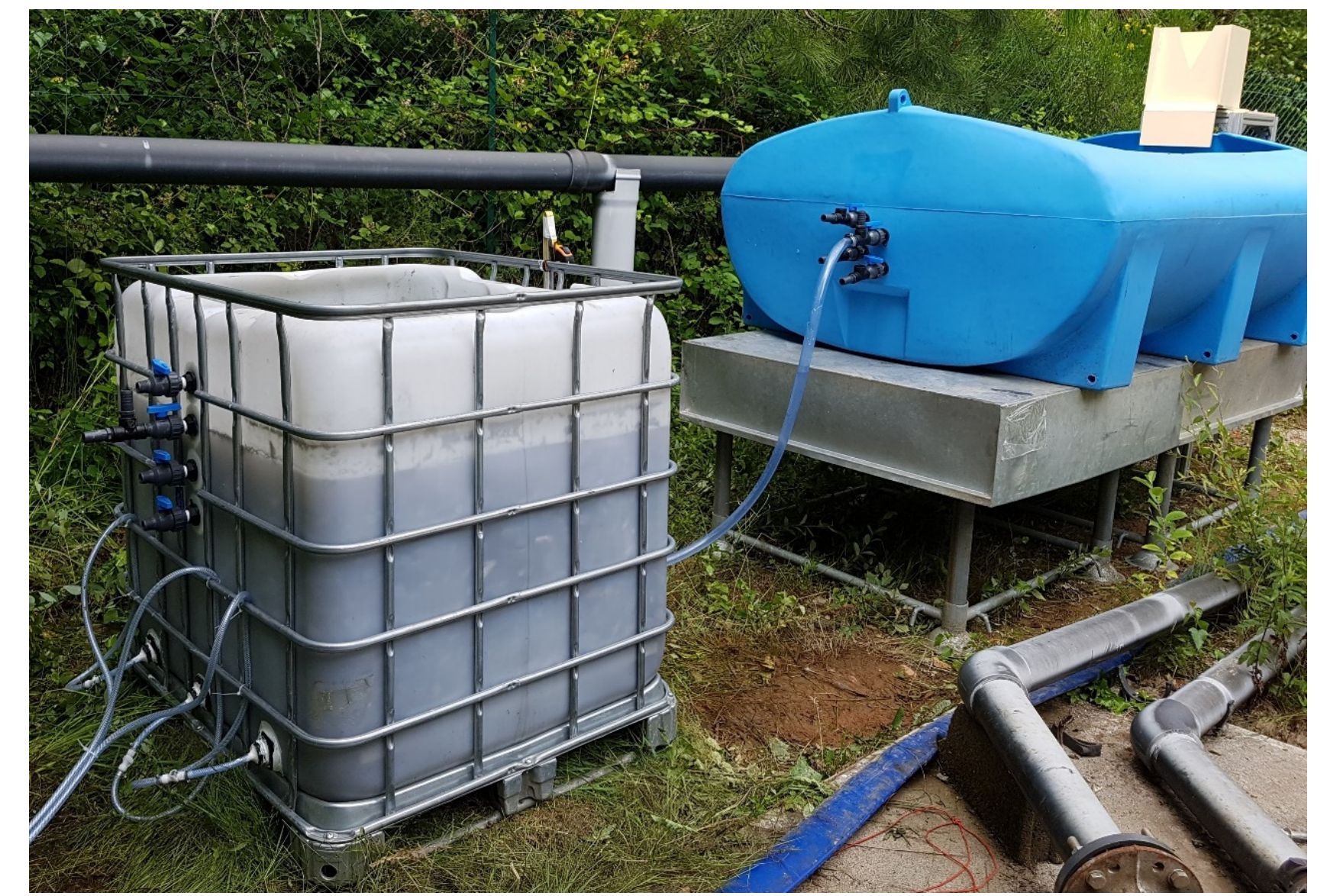

Figure 2 Picture of the pilot plant on site

\subsection{Analytical methods}

Samples were taken and measurements made at the inlet and at the outlet of the settling tank and in the outlet of the fixed-bed bioreactor. During the first two months, measurements were taken every day and samples were taken every two days. After two months measurements and samples were taken every two weeks. pH, redox, and dissolved oxygen were measured using a WTW Multi 3620 with Sen Tix 940, Sen Tix ORP-T900 and FDO925 probes respectively. For each sampling point, two water samples were taken. The first one was immediately filtered using $0.45 \mu \mathrm{m}$ filters for analysis of dissolved iron and manganese. The second one was not filtered for analysis of total $\mathrm{Fe}$ and $\mathrm{Mn}$. All samples were acidified at $\mathrm{pH} 2$ with nitric acid $\left(\mathrm{HNO}_{3}\right)$ $67 \%$. Iron concentrations were measured by UV-visible spectrophotometry using FerroVer $\mathrm{HACH}$ PERMACHEM REAGENTS containing 10-phenanthroline. Manganese concentrations were measured using HACH PERMACHEM REAGENTS containing Ascorbic Acid. Flow rates were checked using a graduated container and a stopwatch.

\section{Results}

Water in the settling tank and in the bioreactor was always saturated with dissolved oxygen. The aeration tank was not necessary to ensure proper oxygenation. Average dissolved oxygen level in the settling tank was $7.94 \mathrm{mg} . \mathrm{L}^{-1}$ during condition 1 and $7.80 \mathrm{mg} . \mathrm{L}^{-1}$ during condition 2 .

While the water temperature at the inlet was steady at $16.2 \pm 0.1^{\circ} \mathrm{C}$, temperature in the settling tank and in the bioreactor decreased significantly over time. Average temperature in the settling tank was $25.4^{\circ} \mathrm{C}$ during condition 1 and $9.8^{\circ} \mathrm{C}$ during condition 3 . There were very little temperature differences between the settling tank and the bioreactor. 
No differences in water level between the upstream and downstream of the fixed-bed bioreactor were observed. The absence of pressure drop in the bioreactor shows that there was very little clogging after 157 days of operation.

The effluent pH increased from 6.33 at inlet to 6.92 in the settling tank during the 3 tested conditions as shown in Figure 3. In the limestone bioreactor, average $\mathrm{pH}$ was 7.87 during condition 1, 7.79 during condition 2 and 7.23 during condition 3 . The effluent $\mathrm{pH}$ increase in the settling tank can be explained by the naturally high alkalinity of the water and the degassing of $\mathrm{CO}_{2}$ during the aeration (Kirby \& Cravotta 2005) according to Equation 1.

$$
\mathrm{H}^{+}+\mathrm{HCO}_{3}^{-} \rightarrow \mathrm{CO}_{2}+\mathrm{H}_{2} \mathrm{O}
$$

Increase of $\mathrm{pH}$ between the settling tank and the bioreactor is obvioulsy due to the limestone filling. The decrease of $\mathrm{pH}$ in the bioreactor over time can be explained by the armoring of limestone by manganese oxide and the decrease of water retention time between condition 1 and 3 .

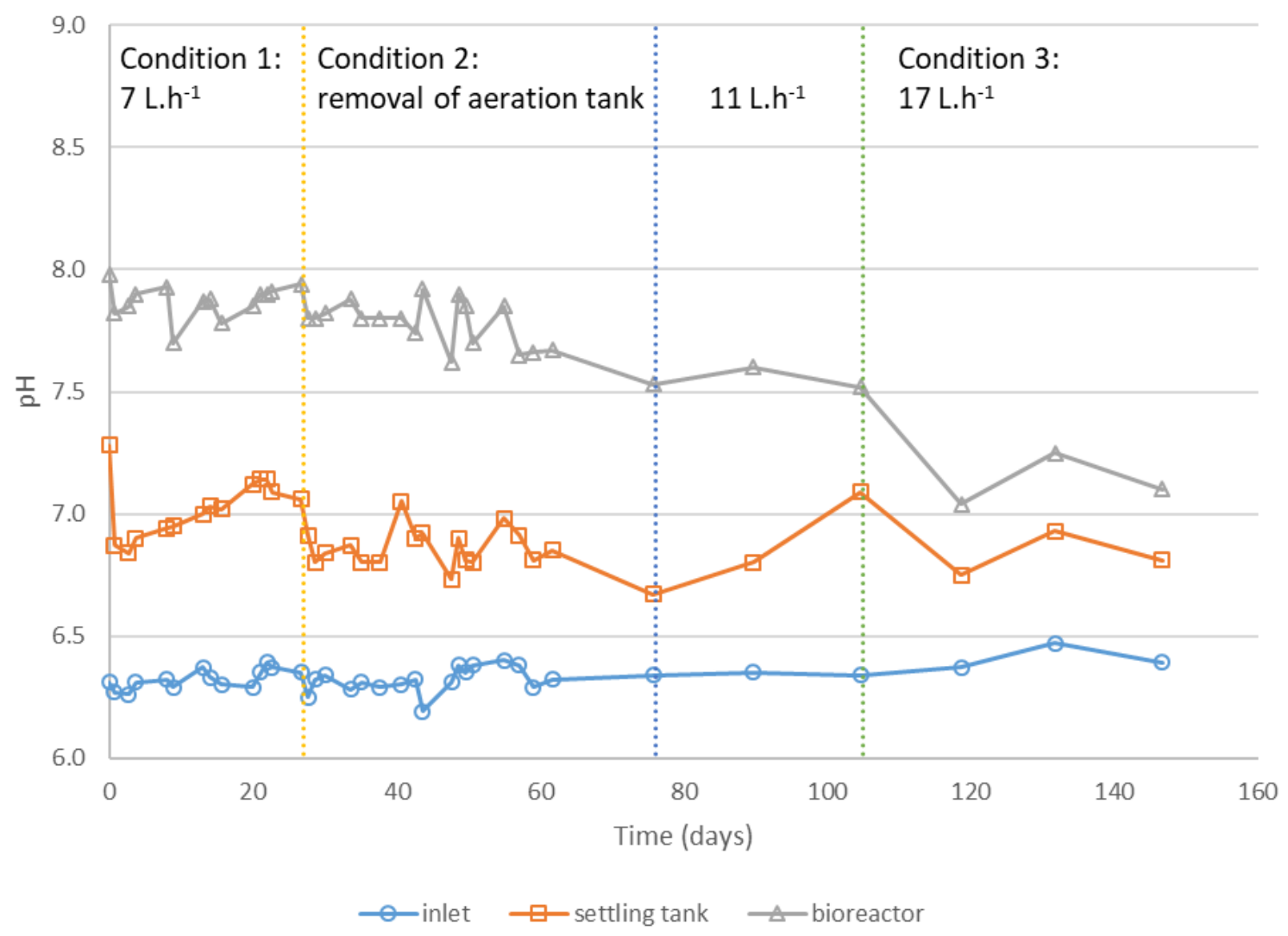

Figure $3 \mathrm{pH}$ in the pilot plant

Figure 4 shows that the removal of the aeration tank did not affect iron concentration in the settling tank. However, it is apparent that at $17 \mathrm{~L} . \mathrm{h}^{-1}$ iron concentration increases in the settling tank up to $7 \mathrm{mg} . \mathrm{L}^{-1}$. This result suggests that the residence time is no longer sufficient to remove all dissolved iron. During the entire pilot operation, iron concentration in the bioreactor remained very low. 


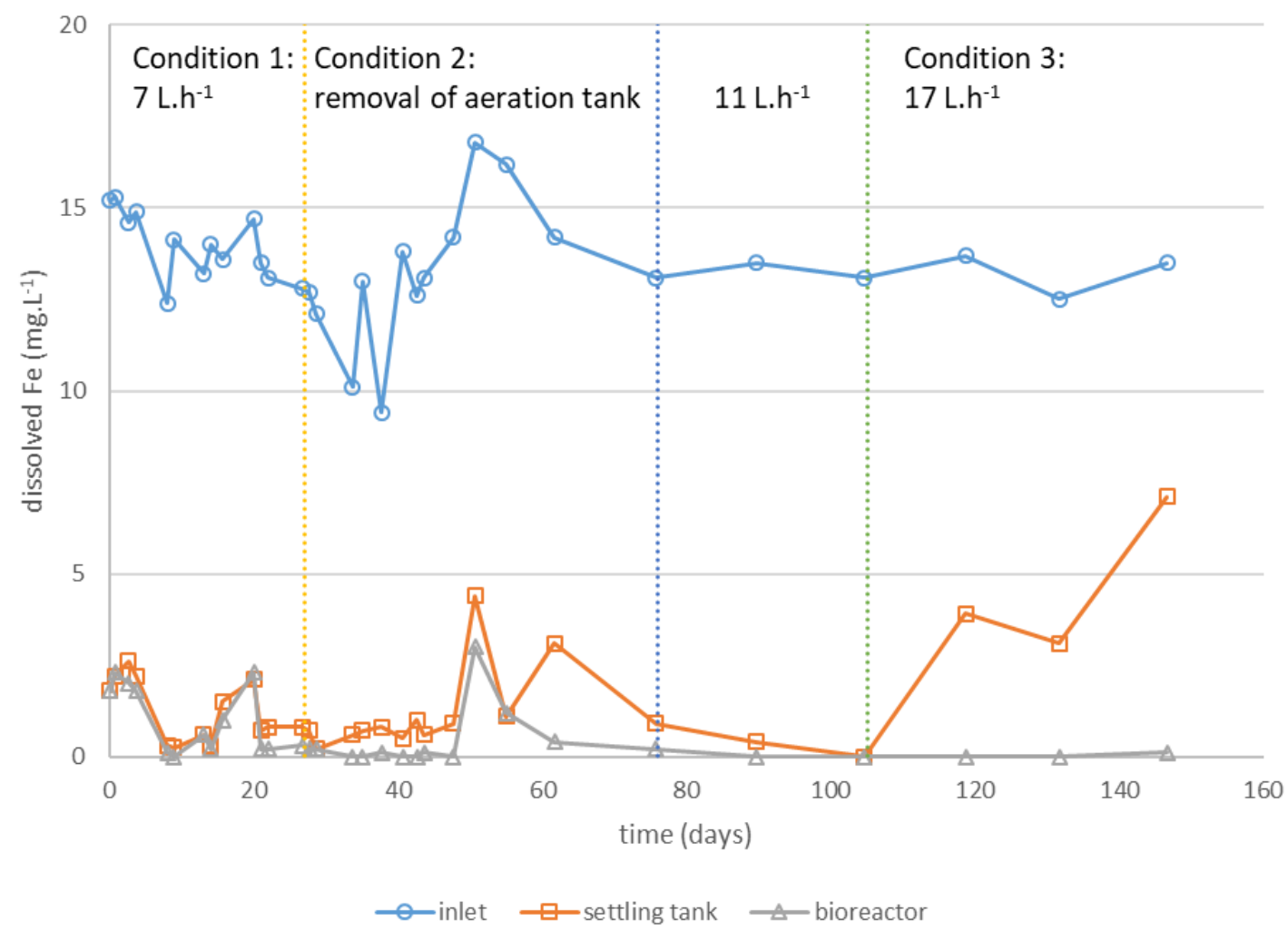

Figure 4 Dissolved iron levels in the pilot plant

During conditions 1 and 2, manganese concentration decreases from $12 \mathrm{mg} \cdot \mathrm{L}^{-1}$ at the inlet to $7 \mathrm{mg} \cdot \mathrm{L}^{-1}$ in the settling tank and to $0 \mathrm{mg} \cdot \mathrm{L}^{-1}$ in the bioreactor (Figure 5). The removal of the aeration tank did not affect

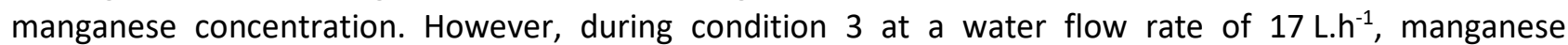
concentration increased to $10 \mathrm{mg} \cdot \mathrm{L}^{-1}$ in the settling tank and to $2 \mathrm{mg} \cdot \mathrm{L}^{-1}$ in the bioreactor.

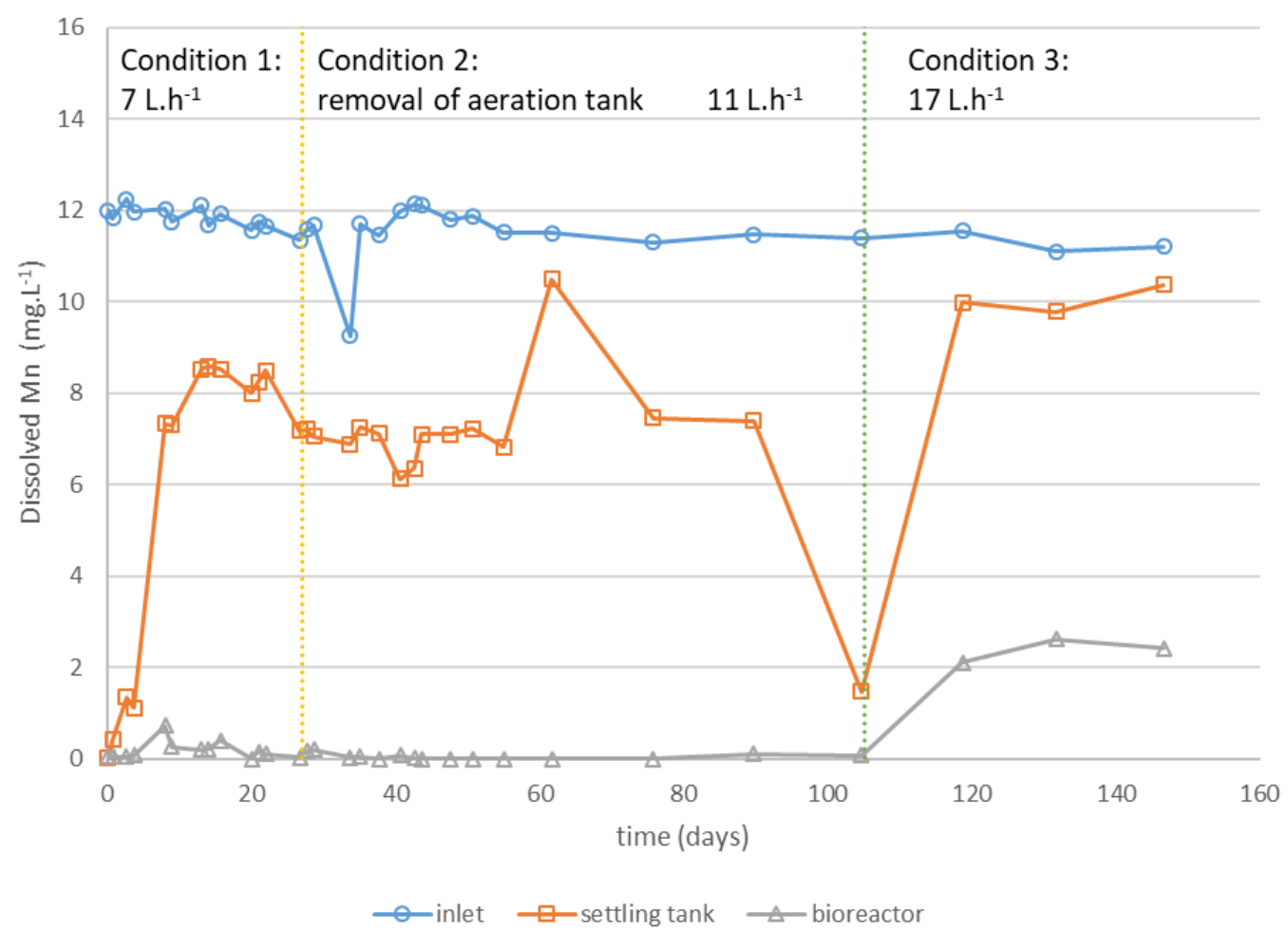

Figure 5 Dissolved manganese levels in the pilot plant 
Table 2 summarises the average dissolved iron and manganese removal measured in the pilot plant. The results of conditions 1 and 2 are closely matched. As expected based on the kinetics measured at laboratory scale (data not shown), residence time in the settling tank was sufficient to remove most of the iron (90\%). However, the significant manganese removal in the settling tank (38\%) was surprising. The complete removal of manganese in the bioreactor indicates that the residence time was longer than necessary. These results suggest that the bioreactor performances are better than expected or it can be due to the significant and unexpected removal of manganese in the settling tank. During condition 3, iron removal decreased to $65 \%$ in the settling tank, but iron was still fully removed in the bioreactor. Manganese removal in the settling tank decreased significantly to $11 \%$, however, did not reach $0 \%$. In the bioreactor, manganese removal decreased to $76 \%$, which means that the residence time was no longer sufficient to treat the remaining iron and the manganese.

Table 2 Average dissolved iron and manganese removal in the settling tank and the bioreactor during the pilot experiment

\begin{tabular}{lllll}
\hline Parameter & Units & Condition 1 & Condition 2 & Condition 3 \\
\hline Fe removal in settling tank & $\%$ & 93 & 90 & 65 \\
Mn removal in settling tank & $\%$ & 38 & 38 & 11 \\
Fe removal in bioreactor & $\%$ & - & - & 100 \\
Mn removal in bioreactor & $\%$ & 97 & 100 & 76 \\
\hline
\end{tabular}

\section{Discussion}

Iron and manganese removal rates in the pilot were calculated for each condition and they are presented in Table 3. The iron removal rate increased from 85 to $135 \mu \mathrm{g} \cdot \mathrm{L}^{-1} \cdot \mathrm{h}^{-1}$ between conditions 1 and 3 because iron oxidation rate follows first order kinetics with respect to $\mathrm{Fe}^{2+}$ concentration (Morgan \& Lahav 2007). During condition 3 , iron removal rate was much more important in the bioreactor than in the settling tank because $\mathrm{pH}$ was higher and because limestone retained iron oxides solid phases, which promote the quick heterogeneous oxidation of iron (Sapsford et al. 2007). In this context of limited surface area, the use of a settling pond to treat iron should be carefully considered, although this solution is very traditional, easy to implement and to maintain.

Manganese oxidation can occur at a pH of 6 to 9 (Sikora et al. 2000), but the reaction must be catalysed by manganese oxide precipitates via heterogeneous oxidation (Stumm \& Morgan 2012), and/or by microorganisms (Bender et al. 1994). The settling tank does not contain solids with large surface area to fix microorganism or manganese oxides. However, although manganese removal speed in the settling tank was low $\left(30 \mu \mathrm{g} \cdot \mathrm{L}^{-1} \cdot \mathrm{h}^{-1}\right)$, it remained significant since it allowed the removal of $38 \%$ of manganese in condition 1 and 2 . It is possible that a population of planktonic microorganisms established in the pond and a biofilm may have covered the tank surface. Microbiological sampling and analysis will be conducted to investigate this hypothesis. In any case, these results show that the treatment of iron and manganese in the same pond is possible if the residence time is long enough.

The manganese removal rate in the settling tank decreased from 30 to $20 \mu \mathrm{g} \cdot \mathrm{L}^{-1} \cdot \mathrm{h}^{-1}$ between conditions 1 and 3 , which means that the decrease in manganese removal in the settling tank is not only a consequence of the decrease in residence time. It may also be explained by the increase of $\mathrm{Fe}^{2+}$ concentration in the settling tank to $5 \mathrm{mg} \cdot \mathrm{L}^{-1}$. Ferrous iron is known to limit manganese removal by reducing oxidised manganese precipitates back into soluble Mn(II) (Hedin et al. 1994; Burdige et al. 1992).

The manganese removal rate increased from 142 to $358 \mu \mathrm{g} \cdot \mathrm{L}^{-1} \cdot \mathrm{h}^{-1}$ between conditions 1 and 3 . Since the bioreactor can no longer treat all manganese, this removal speed could be considered as an optimum. However, this is still much lower than the speeds reported on a similar set-up by Johnson \& Younger (2005) $\left(2,500 \mu \mathrm{g} \cdot \mathrm{L}^{-1} \cdot \mathrm{h}^{-1}\right)$ or by Duarte \& Ladeira (2011) $\left(30,300 \mu \mathrm{g} \cdot \mathrm{L}^{-1} \cdot \mathrm{h}^{-1}\right)$. In our experiment, the bioreactor also 
received and treated some iron during condition 3 . Thus, manganese removal rate in the bioreactor may be even faster without the adverse effect of ferrous iron.

Table 3 Average iron and manganese removal rate in the settling tank and the bioreactor during the pilot experiment

\begin{tabular}{lllll}
\hline Parameter & Units & Condition 1 & Condition 2 & Condition 3 \\
\hline Fe removal speed in settling tank & $\mu \mathrm{g} \cdot \mathrm{L}^{-1} \cdot \mathrm{h}^{-1}$ & 85 & 82 & 134 \\
Mn removal speed in settling tank & $\mu \mathrm{g} \cdot \mathrm{L}^{-1} \cdot \mathrm{h}^{-1}$ & 30 & 30 & 20 \\
Fe removal speed in bioreactor & $\mu \mathrm{g} \cdot \mathrm{L}^{-1} \cdot \mathrm{h}^{-1}$ & - & - & 216 \\
Mn removal speed in bioreactor & $\mu \mathrm{g} \cdot \mathrm{L}^{-1} \cdot \mathrm{h}^{-1}$ & 142 & 146 & 358 \\
\hline
\end{tabular}

\section{Conclusion}

A pilot plant composed of a settling tank and an aerated fixed-bed bioreactor filled with limestone and pyrolusite has been operated for 147 days to treat the neutral mine drainage, rich in iron and manganese, of the closed Burg mine. The removal efficiency reached $100 \%$ for both iron and manganese with a water residence time of $150 \mathrm{~h}$ in the settling tank and $50 \mathrm{~h}$ in the bioreactor. Surprisingly, up to $30 \%$ of the manganese could be removed in the settling tank. With a residence time of $60 \mathrm{~h}$ in the settling tank and $20 \mathrm{~h}$ in the bioreactor, removal rates were $100 \%$ for iron and $75 \%$ for manganese. Maximum removal rates in the bioreactor were $358 \mu \mathrm{g} \cdot \mathrm{L}^{-1} \cdot \mathrm{h}^{-1}$ for manganese and $216 \mu \mathrm{g} \cdot \mathrm{L}^{-1} \cdot \mathrm{h}^{-1}$ for iron. In the settling tank, maximum removal rate of iron was only $134 \mu \mathrm{g} \cdot \mathrm{L}^{-1} \cdot \mathrm{h}^{-1}$. After 147 days of operation, the fixed-bed bioreactor displayed no signs of clogging.

The pilot will continue to be operated for a few months during which several parameters will be studied. The oxygen uptake rate will be determined and the injected gas flow rate will be optimised. The water flow rate will be decreased and the volume of the bioreactor will be decreased in order to remove all iron in the settling tank and assess the optimal manganese removal speed in the bioreactor. The pressure drop in the bioreactor will continue to be monitored and the sludge from the settling tank will be characterised at the end of the pilot study. A variant of the bioreactor based on a wetland type design to oxygenate the waters with plants growing on a substrate similar to bed of the bioreactor will also be assessed in parallel.

Finally, all results will be integrated in the design of a real-scale treatment scheme.

\section{Acknowledgement}

This study was carried out by BRGM with funding from Rio Tinto France. The authors thank Julie Mirlocca, Francis Boularan, Dominique Breeze, Elise Decouchon, Bruno Lemière, and Vincent Sautereau for their help.

\section{References}

Barboza, NR, Guerra-Sá, R \& Leão, VA 2016, 'Mechanisms of manganese bioremediation by microbes: an overview', Journal of Chemical Technology \& Biotechnology, vol. 91, no. 11, pp. 2733-2739.

Bender, J, Gould, JP, Vatcharapijarn, Y, Young, JS \& Phillips, P 1994, 'Removal of zinc and manganese from contaminated water with cyanobacteria mats', Water Environment Research, vol. 66, no. 5, pp. 679-683.

Burdige, DJ, Dhakar, SP \& Nealson, KH 1992, 'Effects of manganese oxide mineralogy on microbial and chemical manganese reduction', Geomicrobiology Journal, vol. 10, no. 1, pp. 27-48.

Duarte, RA \& Ladeira, AC 2011, 'Study of manganese removal from mining effluent', TR Rüde, A Freund \& C Wolfersdorfer (eds), Proceedings of the 11th International Mine Water Association Congress - Mine Water-Managing the Challenges, International Mine Water Association, Aachen, pp. 297-300.

Hedin, RS, Nairn, RW \& Kleinmann, RL 1994, Passive treatment of coal mine drainage, United States Department of the Interior, Bureau of Mines, Washington DC.

Howe, P, Malcolm, H \& Dobson, S 2004, Manganese and its compounds: environmental aspects, Concise International Chemical Assessment Document 63, World Health Organization, Geneva. 
Johnson, KL \& Younger, PL 2005, 'Rapid manganese removal from mine waters using an aerated packed-bed bioreactor', Journal of Environmental Quality, vol. 34, no. 3, pp. 987-993.

Kirby, CS \& Cravotta III, CA 2005, 'Net alkalinity and net acidity 2: practical considerations', Applied Geochemistry, vol. 20, issue 10, pp. 1941-1964, https://doi.org/10.1016/j.apgeochem.2005.07.003

Morgan, B \& Lahav, O 2007, 'The effect of pH on the kinetics of spontaneous Fe (II) oxidation by 02 in aqueous solution-basic principles and a simple heuristic description', Chemosphere, vol. 68, no. 11, pp. 2080-2084, https://doi.org/10.1016/j.chemosphere.2007.02.015

Neculita, CM \& Rosa, E 2018, 'A review of the implications and challenges of manganese removal from mine drainage', Chemosphere, vol. 214, pp. 491-510, https://doi.org/10.1016/j.chemosphere.2018.09.106

Sapsford, D, Barnes, A, Dey, M, Williams, K, Jarvis, A \& Younger, P 2007, 'Low footprint passive mine water treatment: field demonstration and application', Mine Water and the Environment, vol. 26, no. 4, pp. 243-250.

Sikora, FJ, Behrends, LL, Brodie, GA \& Taylor, HN 2000, 'Design criteria and required chemistry for removing manganese in acid mine drainage using subsurface flow wetlands', Water Environment Research, vol. 72, no. 5, pp. 536-544.

Stumm, W \& Morgan, JJ 2012, Aquatic Chemistry: Chemical Equilibria and Rates in Natural Waters, John Wiley \& Sons, Hoboken.

Tan, H, Zhang, G, Heaney, PJ, Webb, SM \& Burgos, WD 2010, 'Characterization of manganese oxide precipitates from Appalachian coal mine drainage treatment systems', Applied Geochemistry, vol. 25, no. 3, pp. 389-399, https://doi.org/10.1016/j.apgeochem.2009.12.006

United States Department of Health and Human Services 2012, Toxicological profile for manganese, The Agency for Toxic Substances and Disease Registry, Atlanta.

United States Environmental Protection Agency 2014, Reference Guide to Treatment Technologies for Mining-influenced Water, EPA 542-R-14-001.

Vail, WJ \& Riley, R 2000, 'The pyrolusite process: a bioremediation process for the abatement of acid mine drainage', Green Lands, vol. 30, no. 4, pp. 40-46. 
